\title{
Management Pathway for Pyonephrosis
}

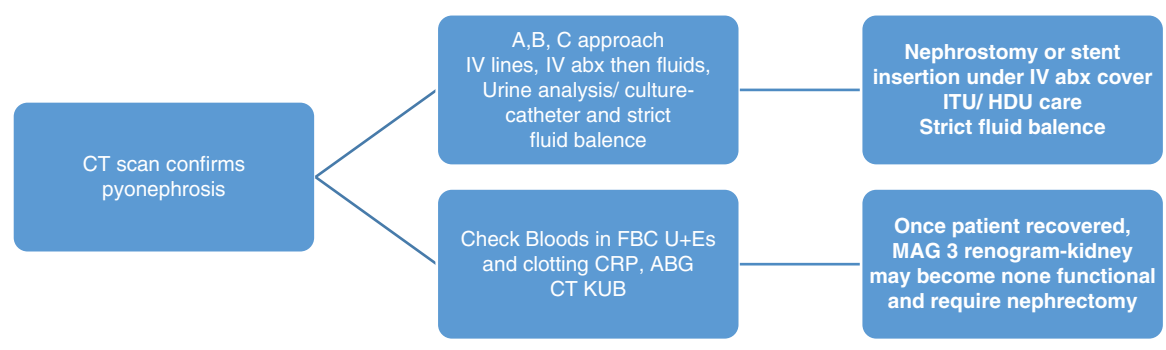

\section{Suggested Reading}

Ludvigson AE, Beaule LT. Urologic emergencies. Surg Clin North Am. 2016;96(3):407-24.

Naber KG, Bergman B, Bishop MC, Bjerklund-Johansen TE, Botto H, Lobel B, Jinenez Cruz F, Selvaggi FP. EAU guidelines for the management of urinary and male genital tract infections. Urinary Tract Infection (UTI) Working Group of the Health Care Office (HCO) of the European Association of Urology (EAU). Eur Urol. 2001;40(5):576-88.

Sow Y, Fall B, Sarr A, Thiam A, Diao B, Fall PA, Ndoye AK, Ba M, Diagne BA. Pyonephrosis: 44 cases in Senegal. Med Trop (Mars). 2011;71(5):495-8. 